\title{
REVIEW
}

\section{If you want to cure their asthma, ask about their job}

\author{
James D.M. Douglas*
}

\author{
Tweeddale Medical Practice, High Street,
}

Fort William, Scotland PH33 6EU, UK
Received 6 December 2004; accepted 10 December 2004 ractice AirWays GrOUP

KEYWORDS

Asthma;

Occupational asthma;

Primary care;

General Practitioners;

Guidelines;

Peak flows;

Sero conversion
Sumnary Occupaticra (1) asthnal is the most common occupational respiratory disorder and a cocunts isr $15 \%$ of cases of adult asthma. A recent systematic review of e 'itence and management has clarified patient care for General Practitioners (GPs) who are key professionals in early diagnosis.

Exposure to respirable agents in the work environment by means of dust, water aerosol or gases, causes an allergic sensitisation process in the respiratory tract. Initial rhinitis and night cough may progress to patterns of work-related wheezing from two weeks to six months after starting employment. The absence of symptoms while on holiday or sick leave suggests the diagnosis. Serial peak flow recordings show characteristic patterns. Smoking and atopy have a variable influence on whether a worker will develop the disease with exposure.

Early identification and removal from exposure is essential for the worker since it improves prognosis. Other workers will be at risk, and occupational hygienists are required to measure and improve the working environment by means of ventilation and extraction of toxic fumes.

Workplaces with workers who are at risk of occupational asthma, such as paint sprayers, food processors, welders and animal handlers, require health surveillance programmes for new and existing employees, as well as reinforcement of the more important primary safety measures of environmental monitoring and respiratory protection.

All clinicians responsible for asthma management need to be aware of the potential for occupational asthma in new cases of adult asthma or unexplained worsening of pre-existing asthma. Specialist help is required to confirm the diagnosis, which has substantial legal and economic implications for the worker and their employer. (c) 2004 General Practice Airways Group. Published by Elsevier Ltd. All rights reserved.

* Tel.: +44 1397 703136; fax: +44 1397 700139;

Mobile: 07768485268.

E-mail address: james.douglas@tweeddale.com. 


\section{Contents}

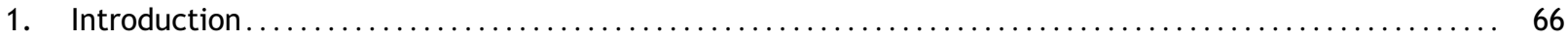

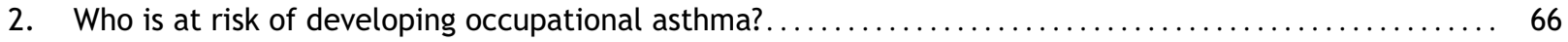

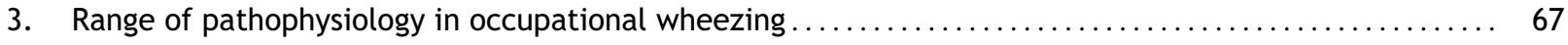

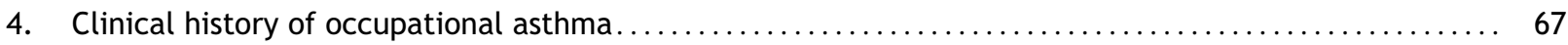

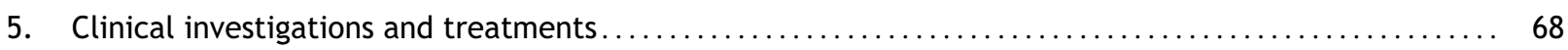

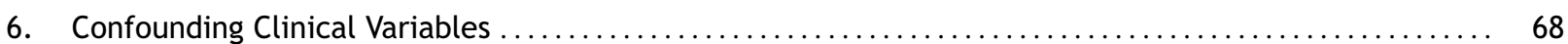

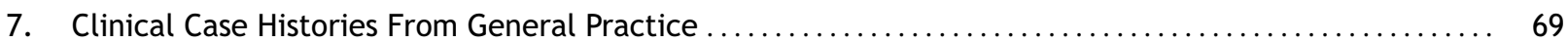

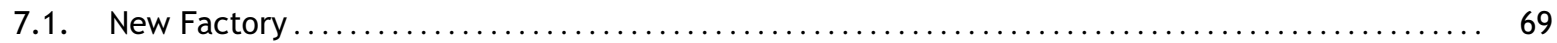

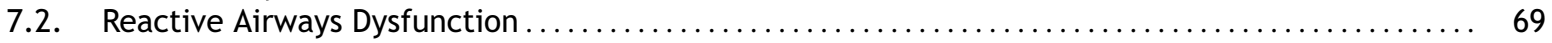

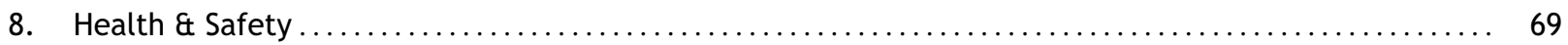

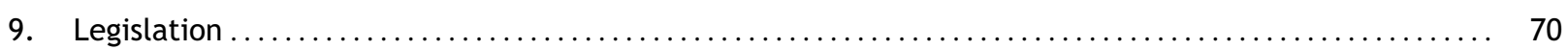

10. What to do if you suspect a patient has occupational asthma.......................... 70

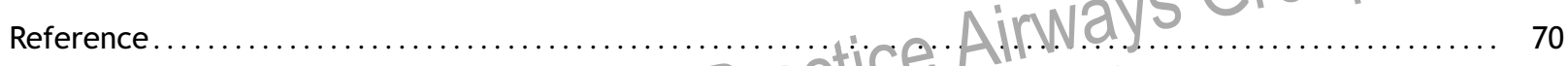

\section{Introduction}

New-onset adult asthma or aggravation of existing asthma should always raise the clinical question as to whether work is a contributing factor.

Occupational asthma accounts for up to $15 \%$ of all adult asthma and is the most commonly reported occupational respiratory disorder in Westernised industrial countries [1]. Occupational asthma has a poor prognosis unless it is identified early and managed effectively by removing the patient from exposure to the causative agent $[2,3]$.

Health surveillance screening should be conducted at least annually and more frequently in the first two years of exposure. Workers who have pre-existing asthma and those who develop rhinitis require extra monitoring. Skin prick testing and immunological surveillance can help confirm the diagnosis together with the clinical history and lung function tests, but positive results by themselves do not indicate disease, merely sero-conversion. Workers with confirmed occupational asthma should be removed from exposure at the earliest opportunity and the whole workforce reassessed. Regular environmental measurements and prevention of allergen inhalation remain the cornerstones of prevention $[2,3]$.

The chronic phase of occupational asthma is difficult to recognise clinically, and long-term exposure causes permanent asthma - in contrast to those individuals who are identified early and effectively
Box 1

British Occupational Health Research

Foundation

http: / / www.bohrf.org.uk

Health \& Safety Executive

http: / / www.hse.gov.uk/asthma

General Practice Airways Group

http: / / www.gpiag.org

OASYS and Occupational Asthma

http: / / www.occupationalasthma.com

BTS/SIGN Guidelines

http://www.sign.ac.uk

cured of their asthma once removed from exposure $[2,3]$.

A systematic review and publication of clinical guidelines by the British Occupational Health Research Foundation has been a welcome development in clinical management - for relevant web sites, refer to Box 1.

\section{Who is at risk of developing occupational asthma?}

The most commonly reported occupations leading to occupational asthma include:

Animal handlers

Laboratory workers 
Box 2

High Molecular Weight Causative Agents

Prawn processing

Salmon processing

Bakery flour

Animal fur and urine

Biological detergent manufacture

Pharmaceuticals, e.g. amoxycillin production

Low Molecular Weight Causative Agents

Western Red Cedar asthma (plicatic acid) Isocyanites (paint sprays and foams)

Bakers (supermarkets)

Chemical workers (isocyanites)

Food processing workers (prawn processors)

Nurses (latex gloves and endoscopy)

Paint sprayers (isocyanites)

Timber workers (wood dusto and $r$ esurs)

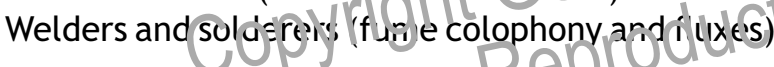

Occupational asthma tends to occur in clusters of cases following the development of new work processes and failure to apply existing knowledge on safe working practices.

The respirable agent needs to be of respirable size in particle form, or suspended in water aerosol or gases. The allergic reaction tends to occur at bronchiolar level and the causative agents can broadly be separated into high molecular weight and low molecular weight agents (see Box 2).

\section{Range of pathophysiology in occupational wheezing}

The causative agent needs to be of respirable size to reach the right place in the lung. Large particles are blocked in the nose and don't become inhaled. Dust and mist particles are too large to reach the bronchioles. The pharmaceutical science of aerosol and dry powder inhaler production helps one to understand the concept of respirable size and lung deposition. A respirable particle size of 3-4 microns is likely to cause a reaction and we know that long thin asbestos fibres reach the alveoli. The classical pathophysiological process in occupational asthma is an lgE-mediated sensitisation which occurs at bronchial and bronchiolar level in the lungs. The allergen may be inhaled directly or suspended in water or gas.
Box 3: Pathophysiology of work-related wheezing

- Occupational asthma-IgE driven sensitisation

- Alveolitis - lgG mediated farmer's lung

- Irritant or corrosive (chlorine gas, powdered weed killer)

In the alveolitis of farmer's lung and malt worker's lung, fungal spores are inhaled to produce an lgG-driven immune reaction in the alveoli. Farmer's lung is often associated with systemic symptoms of shivers and general malaise in addition to breathlessness.

After irritant exposilso due to chlorine inhalation symp chl can follow from a single expoa.ure, Vurilst in classital occupational asthma the respirator. s. Thiptons are exactly the same as "rormalw asthma after a period of sensitisation (Box 3).

\section{Clinical history of occupational asthma}

The onset of symptoms can be anything from two weeks to six months from the start of employment for an adult who has not been asthmatic before. In the early stages, rhinitis and a nocturnal cough might be the first symptoms. During the process of sensitisation to the inhaled allergen, there may be a few weeks or months when the patient feels worse when they go into work. However, a chronic phase quickly supervenes; the patient feels asthmatic all the time and it becomes difficult to distinguish a clear pattern of aggravation whilst at work. The predominant symptom at this stage is an improvement in symptoms at weekends and during days off, but this again progresses to a stage when there is no difference at weekends and the only noticeable improvement occurs during holidays and sickness absence.

Early identification and removal from exposure reduces the likelihood of the patient developing chronic asthmatic symptoms. Patients with occupational asthma can often find it difficult gaining alternative employment and can be economically disadvantaged. The possibility of industrial injuries compensation and litigation makes it essential for the clinician to document accurate clinical records. 
Daily Mean Peak Flow (Case 10)

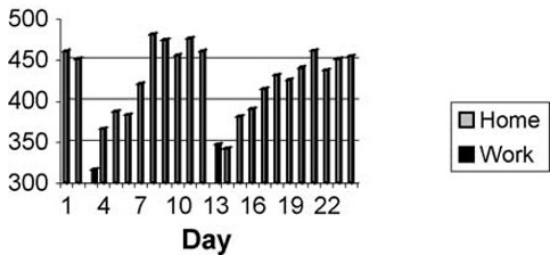

Figure 1

\section{Clinical investigations and treatments}

The cornerstone of diagnostic investigation is the clinical history, as well as peak flow recordings [4] and demonstration of a specific antibody. The diagnosis of asthma is recorded in the conventional manner by demonstrating the reversibility of airway obstruction with salbutamol or steroids. Clarifying the clinical picture, prior to treatment, by measor ing daily mean peak flows during time at ve $1 \mathrm{k}$ and away from work is valuahle, tas seen in rig, 1.

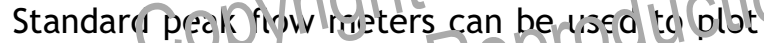
daily mean values related to veriffatterns or during 24-hour shift exposures. Computer programmes to analyse serial peak flow data are under development (http: //www.occupationalasthma.com).

It may be feasible for the GP to sign the patient off work, treat with a course of oral steroids, and then ensure a week of normal peak flows without treatment before the patient returns to work.

The demonstration of specific IgE on serology testing is important, and when the patient is quickly

\section{Investigations for Occupational Asthma}

- Six-hourly peak flow recording

- Bronchial challenge test

- Reversibility with bronchodilators and steroids

- Specific lgG and specific lgE serology identified and removed from exposure, the specific IgE disappears (for example, Fig. 2).

In contrast, delayed identification may cause specific IgE titres to remain raised for up to two years after exposure (for example, Fig. 3 ).

Bronchial challenge testing in the respiratory laboratory, and pre- and post-shift lung volumes with spirometry can all be used Uogain objective evidence.

\section{6 . 0 onfulinding Clinical Variables}

Exposure and sensitisation are required for a diagnosis of occupational asthma, but the influence of personal atopy is variable. With some causative agents, pre-existing atopy is an additional risk factor for developing occupational asthma [5] (e.g. detergent enzymes, laboratory animal asthma, isocyanites, bakery), whereas with other agents, cases are no more prevalent in atopic members of the population (e.g. gluteraldehyde, salmon, crab, platinum).

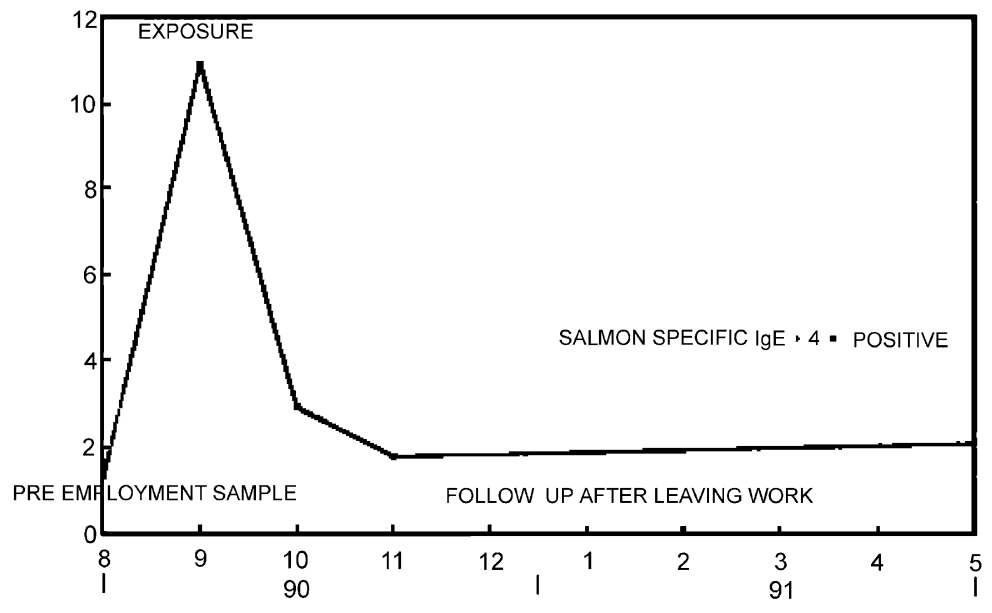

RESPIRATORY GRADE 5 CASE 10 


\section{SALMON SPECIFIC IgE / DATE \\ 6.F.12}

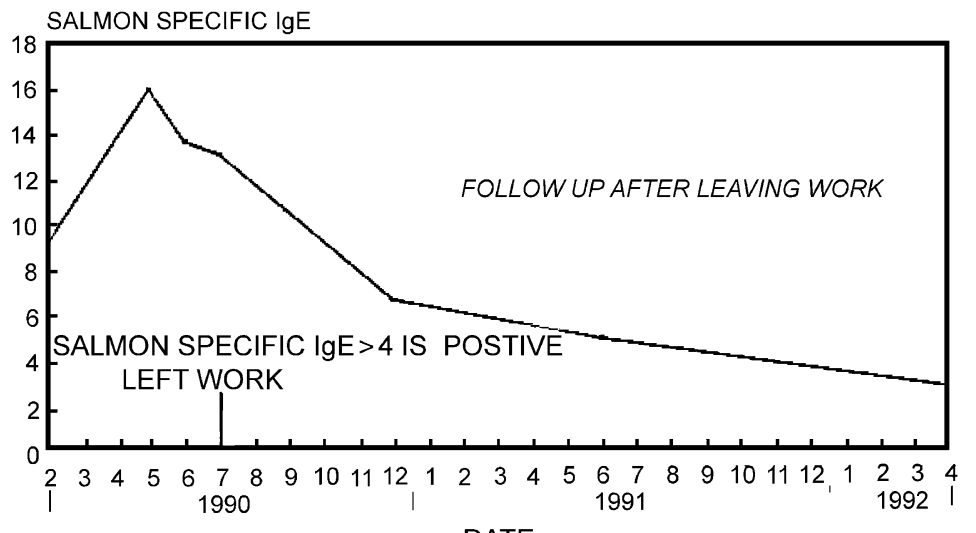

DATE

RESP. GRADE 5 CASE 7

Figure 3

Similarly, smoking may have cortradictoc; effects. In some causes i occupational asthma, smoking increases tre twelihosd of deyeloping the condition [6] (e.g. isocyanites, Filatinum salts, salmon, snow crab) whereas, with other agents, smoking can be a protective variable [5] (e.g. bakers, farmer's lung, Plicatic acid, western red cedar asthma).

\section{Clinical Case Histories From General Practice}

\subsection{New Factory}

A new industrial salmon-processing plant was established in a small rural town and three new cases of adult-onset asthma presented to a local GP. Comprehensive study of the factory demonstrated $8 \%$ prevalence in the workforce, and water aerosol containing salmon protein from the automated gutting machines as the cause. Engineering modifications eliminated the aerosol and no new cases have been observed [6].

\subsection{Reactive Airways Dysfunction}

A 29-year old man presented acutely to his GP after inhaling weed killer dust, while employed by the local authority to clear a ferry slipway. Clinical examination noted respiratory distress which worsened over the following days and required admission and investigation. Lung volumes werlelieduced and severe symptoms of Vieactive airways dysfunction were noticed for at least two years; this meant that he was physically incapable of work due to breathlessness.

Ten years later, he now works in an office and his symptoms have gradually improved - but he still requires inhalers and can be compromised by winter respiratory infections. His lung volumes have been permanently damaged by a single episode of inhaling dust at work. He hadn't been issued with respiratory protection, despite the local authority having had a similar industrial accident at another regional depot one year previously.

\section{Health \& Safety}

The potential to inhale toxic fumes or allergens in the workplace should be at the forefront of safety considerations for personnel managers and process engineers. Predictable hazards from car spray painting and welding need to be considered and engineered out by ventilation and extraction systems.

'Occupational hygiene' is the science of monitoring the environment of the workplace - for example, making measurements for respirable particles and checking air flow and ventilation systems. Occupational hygienists need to advise process engineers and factory designers on the modifications required to make factories safe. 
In laboratory-animal asthma, occupational hygiene measurements have demonstrated that the antigenic challenge mainly comes from animal urine rather than the fur. Extraction of contaminated air and the provision of clean filtered air to the workers' breathing zone is preferable to having to wear face masks, which are often uncomfortable and ineffective. Compliance with personal protective equipment by workers always remains a difficult issue for factory managers.

Health surveillance of workers should be considered for all populations at risk of occupational asthma. Pre-employment screening questionnaires and baseline lung function can protect both employee and employer. However, there is no evidence-based justification to exclude from employment people with poorly discriminating factors such as atopy, a family or personal history of asthma, cigarette smoking or specific HLA phenotypes. Employees should be made av are of the risk of developing orsunaticnal alth ma and the requirement to reperr farcy symptoms [2].

Health surveilance screeringshouid be conducted at least annually and more frequently in the first two years of exposure. Workers who have pre-existing asthma and those who develop rhinitis require extra monitoring. Skin prick testing and immunological surveillance can help case confirmation together with a good clinical history and lung function tests, but positive results by themselves do not indicate disease, merely sero-conversion. Workers confirmed to have occupational asthma should be removed from exposure at the earliest opportunity and the whole workforce reassessed. Regular environmental measurements and prevention of allergen inhalation remain the cornerstones of prevention $[2,3]$.

\section{Legislation}

The Control of Substances Hazardous to Health Regulations remain the cornerstone of legislation in occupational asthma. They require risk assessment and removal of noxious agents which have the potential to be inhaled. The RIDDOR regulations require employers to report industrial accidents and illnesses to the Health \& Safety Executive. These notifications will trigger visits and assessments from HSE factory inspectors.

GPs should be encouraged to word sickcertificates with clear statements, e.g. "investigation of work-related asthma" or "suspected occupational asthma - report under RIDDOR".

\section{What to do if you suspect a patient has occupational asthma}

A GP has a responsibility to identify occupational asthma in the early stages and to seek specialist help. Obtaining an accurate clinical history and peak flow recordings are part of the GP's early role. Referral to a Chest Physician with an interest in occupational asthma or an Occupational Medicine specialist is advisable, given the medico-legal implications.

Patients are often very reluctant for the diagnosis to be suggested and made by their GP. However, the GP must always consider that other people are being potentially affected and there is a professional duty to pursue the problem and to notify the authorities. The GP's pre-existing relationship with the pacierit, ard (1) independence from the occunato has heaith service, is an asset $v$ 'hictes yery important in individual case managemenc. The patient 1 hay need to be persuaded over some ciln: that they need to give up this particul $x$ employment. The patient's anger at the time can progress through to retrospective grateful appreciation years later when the asthma has resolved.

The GP needs to display patient understanding and meticulous record-keeping as their contribution, with occupational health and chest specialists, to improving the life of the patient. The prize of being able to cure occupational asthma is unique when compared to other forms of asthma, and GPs should always remain open to this possibility when reviewing adults with asthma.

\section{References}

[1] Balmes J, Becklake M, Blanc P, Henneberger P, Kreiss K, Mapp C, et al. American Thoracic Society Statement: Occupational contribution to the burden of airway disease. American Journal of Respiratory \& Critical Care Medicine 2003;167: 787-97.

[2] Padoan M, Pozzato V, Simoni M, Zedda L, Milan G, Bononi I, et al. Long-term follow-up of toluene diisocyanate-induced asthma. European Respiratory Journal 2003;21:637-40.

[3] Cathcart M, Nicholson P, Roberts D, Bazley M, Juniper C, Murray $P$, et al. Enzyme exposure, smoking and lung function in employees in the detergent industry over 20 years. Medical Subcommittee of the UK Soap and Detergent Industry Association. Occupational Medicine (Oxford) 1997;47:473-8.

[4] Anees W, Gannon PF, Huggins V, Pantin CF, Burge PS. Effect of peak expiratory flow data quantity on diagnostic sensitivity and specificity in occupational asthma. European Respiratory Journal 2004;23:730-4.

[5] Cullinan P, Cook A, Nieuwenhuijsen MJ, Sandiford C, Tee RD, Venables KM, et al. Allergen and dust exposure as determi- 
nants of work-related symptoms and sensitization in a cohort of flour-exposed workers; a case-control analysis. Annals of Occupational Hygiene 2001;45:97-103.
[6] Douglas JD, McSharry C, Blaikie L, Morrow T, Miles S, Franklin D. Occupational asthma caused by automated salmon processing. Lancet 1995;346:737-40.

Available online at www.sciencedirect.com

Science@irect

Available online at http://www.thepcrj.com

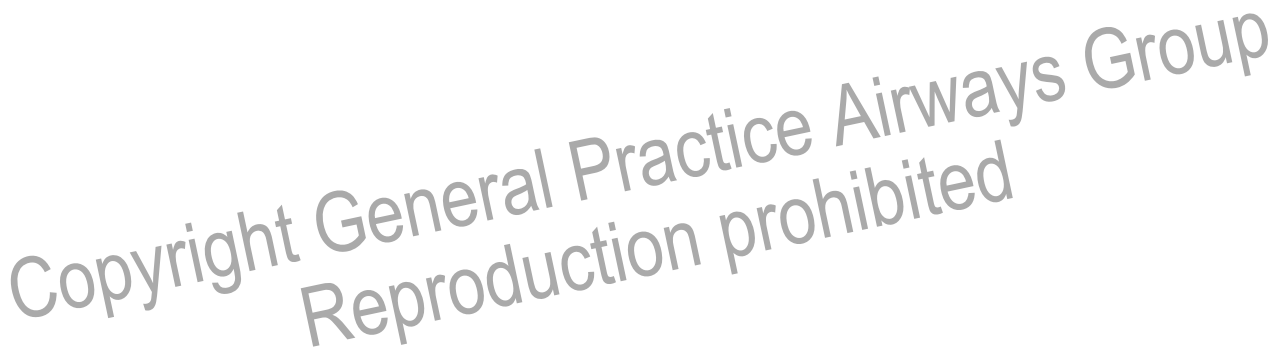

